\title{
Caspase-1 genetic variation is not associated with Alzheimer's disease risk
}

\author{
José Luis Vázquez-Higuera', Eloy Rodríguez-Rodríguez', Pascual Sánchez-Juan', Ignacio Mateo ', Ana Pozueta', \\ Ana Martínez-García², Ana Frank³, Fernando Valdivieso², José Berciano ${ }^{1}$, María J Bullido², Onofre Combarros ${ }^{1 *}$
}

\begin{abstract}
Background: Interleukin (IL)-1 $1 \beta$ is a potent proinflammatory cytokine markedly overexpressed in the brains of patients with Alzheimer's disease (AD), and also involved in development of atherosclerosis and coronary artery disease. Caspase-1 (CASP1), formerly called IL-1 $\beta$ converting enzyme (ICE), mediates the cleavage of the inactive precursor of IL-1 $\beta$ into the biologically active form. CASP1 genetic variation (G+7/in6A, rs501192) has been associated with susceptibility to myocardial infarction and cardiovascular death risk. We examined the contribution of this gene to the susceptibility for AD.
\end{abstract}

Methods: We examined genetic variations of CASP1 by genotyping haplotype tagging SNPs (htSNPs) (rs501192, rs556205 and rs530537) in a group of 628 Spanish AD cases and 722 controls.

Results: There were no differences in the genotypic, allelic or haplotypic distributions between cases and controls in the overall analysis or after stratification by age, gender or APOE $\varepsilon 4$ allele.

Conclusion: Our negative findings in the Spanish population argue against the hypothesis that CASP1 genetic variations are causally related to $A D$ risk.

\section{Background}

A chronic inflammatory process might contribute to the neurodegeneration associated with Alzheimer's disease (AD), by overexpression of cytokines, such as interleukin-1 (IL-1), and other inflammatory molecules in activated microglia surrounding amyloid plaques [1]. Increased expression of IL-1 in AD has been implicated in the formation of amyloid plaques and neurofibrillary tangles, the spread of these neuropathological lesions across cerebral cortical regions, and the accompanying neuronal cell injury and loss [2]. The predominant $\beta$ isoform of IL-1 is generated from an inactive precursor through the action of caspase-1 (CASP1), a cystein protease formerly called IL- $1 \beta$ converting enzyme (ICE), and CASP1 expression appears to be significantly increased in post-mortem brain tissue from patients with AD [3-5]. In addition, CASP1 messenger RNA expression has been closely associated with neurofibrillary tangle and, to a lesser extent, amyloid plaque

\footnotetext{
* Correspondence: combarro@unican.es

"Neurology Service and CIBERNED, "Marqués de Valdecilla" University Hospital (University of Cantabria), Santander, Spain
}

density [4]. Several studies have reported associations between IL-1 $\beta$ genetic polymorphisms and AD, but findings from different studies have been controversial [6]. Although genetic markers of the CASP1 region were not found associated to $\mathrm{AD}$ in recent genome-wide association studies [7-10], Blankenberg et al. [11] sequenced the CASP1 gene in a case-control study of myocardial infarction (MI), and found that CASP1 genetic variation is associated with cardiovascular risk. The present study investigated the genetic variability of the CASP1 in relation to AD risk.

\section{Methods}

The study included $628 \mathrm{AD}$ patients $(65 \%$ women; mean age at study 75.8 years; SD 8.1; range 61-109 years; mean age at onset 72.7 years; SD 7.9; range 60-108 years) who met NINCDS/ADRDA criteria for probable $\mathrm{AD}$ [12]. All AD cases were defined as sporadic because their family history did not mention any first-degree relative with dementia. AD patients were recruited from the Departments of Neurology of University Hospital "Marqués de Valdecilla" (Santander, Spain), and Hospital "La Paz" (Madrid, Spain). The large majority of

\section{Biomed Central}


patients were living in the community and had been referred by their general practitioner; few had been admitted from hospital wards or nursing home facilities. Control subjects were 722 unrelated individuals $(65 \%$ women; mean age 78.7 years; SD 9.3; range 60-104 years) randomly selected from nursing homes. These subjects had complete neurologic and medical examinations that showed that they were free of significant illness and had Mini Mental State Examination scores of 28 or more, which were verified by at least one subsequent annual following-up assessment. The controls arose from the same base population as the cases. The $\mathrm{AD}$ and control samples were Caucasians originating from a limited geographical area in northern Spain (Santander) and from the central area of Spain (Madrid).

Blood samples were taken after written informed consent had been obtained from the subjects or their representatives. The study was approved by the ethical committees of the University Hospital "Marqués de Valdecilla" and the Hospital "La Paz". Genotyping of CASP1 (rs501192 in intron 6, rs556205 in intron 7, and rs530537 in intron 7) polymorphisms was performed by a Taq-Man single-nucleotide-polymorphism assay (Applied Biosystems, Warrington, Cheshire, UK) and an ABI PRISM 7000 or 7900 HT sequence detection systems (Applied Biosystems). We used data from the HapMap project http://www.hapmap.org to select the 3 htSNPs capturing $85 \%$ of CASP1 genetic variability in Caucasians. SNPs were chosen among those with minor allele frequencies $\geq 5 \%$ using Haploview v3.2 software http://www.broad.mit.edu/mpg/haploview with an $\mathrm{r}^{2}$ threshold of 0.8. APOE genotyping was performed by amplification of the 4th exon of the APOE gene by PCR with biotinylated primers, followed by reverse hybridization on nitrocellulose strips, using the INNO-LIPA ApoE assay (Innogenetics NV, Ghent, Belgium), or by HhaI restriction analysis.

Hardy-Weinberg equilibrium (HWE) was calculated for the 3 htSNPs genotypes in the control population using Pearson's $\chi^{2}$ statistics. We assessed pairwise linkage disequilibrium (LD) between the 3 htSNPs by D' and $\mathrm{r}^{2}$ statistics. Haplotype reconstruction and their frequencies in cases and controls were estimated by an expectation-maximization algorithm. Pearson's $\chi^{2}$ statistics were performed to compare allele distribution of the patients and control for each htSNP. Haplotype frequencies were also assessed using Pearson's $\chi^{2}$ using Haploview 3.32 software http://www.broad.mit.edu/mpg/ haploview. Rare haplotypes (total frequency $<0.05$ ) were excluded from the analysis.

\section{Results}

In control groups, no significant deviations from HardyWeinberg equilibrium were found for any of the 3 SNPs (p-values ranging from 0.20 to 0.96 ). As shown in Table 1 , the distribution of the allele and genotype frequencies of the CASP1 htSNPs did not differ significantly between AD and control groups. The three CASP1 htSNPs were in complete LD with each other (with $\mathrm{r}^{2}$ values close to 1.0) forming one block, and therefore, they exhibited a pattern of reduced haplotype diversity, with only four haplotypes captured that did not differ between AD and control groups (Table 2). Our analysis showed the expected association between the APOE $\varepsilon 4$ allele and AD with an OR = $5.92(95 \% \mathrm{CI}=4.60-7.62, \mathrm{p}<0.001)$ for carrying 1 or 2 copies of $\varepsilon 4$ allele. There were no major differences in allele, genotype or haplotype frequencies of CASP1 polymorphisms in our total sample stratified for age, gender or APOE $\varepsilon 4$ allele.

\section{Discussion}

Increasing evidence indicates that IL-1 is involved in both development of atherosclerosis and cardiovascular risk, and CASP1 might play a key role in the proatherogenic effects mediated by IL- $1 \beta$ [11]. Blankenberg et al. [11] investigated whether polymorphisms of the CASP1 gene might influence cardiovascular risk by analyzing cases with myocardial infarction (MI) and controls in British, French and German populations $(\mathrm{n}=1774)$. They sequenced all exons, up to $100 \mathrm{bp}$ of exon/intron junctions and up to $1 \mathrm{~kb}$ of 3 '- and 5'-flanking sequences in CASP1, and found a block of 14 SNPs in

\section{Table 1 Distribution of caspase-1 polymorphisms in} patients and controls

\begin{tabular}{lcc}
\hline Caspase-1 polymorphisms & Patients & Controls \\
\hline rs501192 (intron 6) & & \\
GG & $436(0.72)$ & $519(0.73)$ \\
GA & $151(0.25)$ & $175(0.25)$ \\
AA & $18(0.03)$ & $15(0.02)$ \\
Total & 605 & 709 \\
Allele frequency G/A & $0.84 / 0.16$ & $0.85 / 0.15$ \\
& & \\
rs556205 (intron 7) & & \\
AA & $514(0.82)$ & $606(0.84)$ \\
AC & $109(0.17)$ & $113(0.16)$ \\
CC & $5(0.01)$ & $3(0.00)$ \\
Total & 628 & 722 \\
Allele frequency A/C & $0.90 / 0.10$ & $0.92 / 0.08$
\end{tabular}

$\begin{array}{ccc}\text { rs530537 (intron 7) } & & \\ \text { AA } & 159(0.26) & 200(0.28) \\ \text { AG } & 313(0.52) & 374(0.52) \\ \text { GG } & 134(0.22) & 144(0.20) \\ \text { Total } & 606 & 718 \\ \text { Allele frequency A/G } & 0.52 / 0.48 & 0.54 / 0.46\end{array}$

Figures in parentheses indicate frequencies; $p$-values $>0.05$ for all allelic and genotypic comparisons 
Table 2 Haplotype association analysis between caspase- 1 gene and $A D$

\begin{tabular}{cccc}
\hline $\begin{array}{c}\text { Haplotype } \\
\text { block }\end{array}$ & $\begin{array}{c}\text { Haplotype } \\
\text { frequency }\end{array}$ & $\begin{array}{c}\text { AD, control } \\
\text { frequency }\end{array}$ & p-value \\
\hline GAA & 0.531 & $0.521,0.540$ & 0.32 \\
GAG & 0.319 & $0.324,0.315$ & 0.60 \\
ACG & 0.088 & $0.094,0.082$ & 0.29 \\
AAG & 0.062 & $0.061,0.063$ & 0.83 \\
\hline
\end{tabular}

Haplotype block consists of SNPs: rs501192, rs556205 and rs530537; rare haplotypes (total frequency $<0.05$ ) were excluded from the analysis; $p$-values were not corrected for multiple comparisons.

complete LD covering the whole gene sequence: the CASP1 (G+7/in6A, rs501192) A allele was associated with a lower risk of MI in the British and German populations, and the same allele exhibited a borderline association with prospective cardiovascular death in the German population. Moreover, the CASP1 haplotype carrying the (G+7/in6A, rs501192) A allele was associated with a lower gene expression, supporting the existence of a functional polymorphism within the CASP1 gene. All the 3 tagging SNPs analyzed in our study are located in a single block that is the same haplotype block as described by Blankenberg et al. [11] in their European cohorts. Our main objective was to study the CASP1 rs501192 in intron $6(\mathrm{G}+7 /$ in6A) suggesting CASP1 as a putative gene causing cardiovascular risk, and in addition, we genotyped other SNPs in intron 7 (rs556205 and rs530537). We failed to observe any allele, genotype or haplotype association with AD either in the whole study or in APOE \&4-stratified subgroups in the Spanish population.

Variation in the CASP1 gene has been associated with cognitive function in elderly individuals with normal cognition [13]: subjects carrying the CASP1 rs580253 (exon 6) A allele and rs554344 (3'-UTR) C allele had significantly lower IL- $1 \beta$ production levels and performed better on all executive function tests at baseline and during follow-up compared to homozygous of the wild-type allele. One might postulate that carriers of these CASP1 genetic polymorphisms associated with better memory have a higher "cognitive reserve", and consequently, would have a lower predisposition to AD. Although both of these polymorphisms are in complete linkage disequilibrium with our studied CASP1 genetic variants, we did not find any genetic association with AD risk. Contradictory association of a memory-related genetic polymorphism with either healthy volunteers or AD patients is already well known; for example, the APOE $\varepsilon 4$ allele is the only firmly established genetic susceptibility factor for sporadic AD, but it has been related to better memory in young, healthy volunteers
[14]. Moreover, healthy young, middle aged and elderly carriers of the KIBRA rs17070145 T-allele exhibited a clear advantage in delayed episodic recall compared to individuals lacking the $\mathrm{T}$-allele $[15,16]$, but a further study in a community AD population showed an association of the KIBRA rs17070145 T-allele with an increase AD risk [17], thus resulting inconsistent with previous findings in healthy subjects. Our negative results are probably not due to insufficient statistical power, because our sample size had enough power (86\%) to detect an odds ratio of 1.5 at disease allele frequencies of 0.08. Because we only studied three htSNPs capturing $85 \%$ of CASP1 genetic variability in Caucasians, it might be argued that we have missed a hypothetical disease locus, which would have been detected by analysis of extended haplotypes. However, the complete LD across the CASP1 region in our study argues against this possibility; of note, two recent series in other Caucasian populations [11,13] have also detected a complete LD covering the whole gene sequence. Despite supporting evidence for the biological role of CASP1 in AD exists, according to our data CASP1 genetic variation does not seem to be a risk factor for AD.

\section{Conclusion}

Our negative findings in the Spanish population argue against the hypothesis that CASP1 genetic variations are causally related to $\mathrm{AD}$ risk.

\section{Acknowledgements}

C. Sánchez-Quintana and S. Curiel del Olmo were involved in the DNA sample collections and genotyping analysis from Santander, We thank Drs P. Gil and P. Coria for their cooperation in the generation of the case-control samples from Madrid, and to I. Sastre for the maintenance and control of the DNA bank (Madrid). This work was made possible by the generous participation of the patients, the control subjects, and their families. This study was supported by grants from FIS (PI080139) and CIBERNED (CB06/07/ 0037).

\section{Author details}

"Neurology Service and CIBERNED, "Marqués de Valdecilla" University Hospital (University of Cantabria), Santander, Spain. ${ }^{2}$ Molecular Biology Department and CIBERNED, Centro de Biología Molecular Severo Ochoa (CSIC-UAM), Madrid, Spain. ${ }^{3}$ Neurology Service and CIBERNED, Hospital Universitario La Paz (UAM), Madrid, Spain.

\section{Authors' contributions}

JLVH and ERR performed the genetic studies and reviewed critically the manuscript. PSJ performed the statistical analyses and reviewed critically the manuscript. IM, AP, AMG, AF, FV, JB and MJB reviewed critically the manuscript. OC drafted the manuscript and contributed to its final version. All authors read and approved the final manuscript.

\section{Competing interests}

The authors declare that they have no competing interests.

Received: 26 October 2009

Accepted: 25 February 2010 Published: 25 February 2010 


\section{References}

1. Wyss-Coray T, Mucke L: Inflammation in neurodegenerative disease. A double-edged sword. Neuron 2002, 35:419-32

2. Mrak RE, Griffin WST: Interleukin-1 and the immunogenetics of Alzheimer disease. J Neuropathol Exp Neurol 2000, 59:471-6.

3. Zhu SG, Sheng JG, Jones RA, Brewer MM, Zhou XQ, Mrak RE, Griffin WST: Increased interleukin-1 $\beta$ converting enzyme expression and activity in Alzheimer disease. J Neuropathol Exp Neurol 1999, 58:582-7.

4. Pompl PN, Yemul S, Xiang Z, Ho L, Haroutunian V, Purohit D, Mohs R, Pasinetti GM: Caspase gene expression in the brain as a function of the clinical progression of Alzheimer disease. Arch Neurol 2003, 60:369-76.

5. Ojala J, Alafuzoff I, Herukka SK, van Groen T, Tanila H, Pirttilä T: Expression of interleukin-18 is increased in the brains of Alzheimer's disease patients. Neurobiol Aging 2009, 30:198-209.

6. Di Bona D, Plaia A, Vasto S, Cavallone L, Lescai F, Franceschi C, Licastro F, Colonna-Romano G, Lio D, Candore G, Caruso C: Association between the interleukin-1 $\beta$ polymorphisms and Alzheimer's disease: a systematic review and meta-analysis. Brain Res Rev 2008, 59:155-63.

7. Bertram L, McQueen MB, Mullin K, Blacker D, Tanzi RE: Systematic metaanalyses of Alzheimer disease genetic association studies: the AlzGene database. Nat Genet 2007, 39:17-23.

8. Feulner TM, Laws SM, Friedrich P, Wagenpfeil S, Wurst SH, Riehle C, Kuhn KA, Krawczak M, Schreiber S, Nikolaus S, Förstl H, Kurz A, Riemenschneider M: Examination of the current top candidate genes for AD in a genome-wide association study. Mol Psychiatry 2009, (doi: 10.1038/mp.2008.141).

9. Harold D, Abraham R, Hollingworth P, Sims R, Gerrish A, Hamshere ML, Pahwa JS, Moskvina V, Dowzell K, Williams A, Jones N, Thomas C, Stretton A, Morgan AR, Lovestone S, Powell J, Proitsi P, Lupton MK, Brayne C, Rubinsztein DC, Gill M, Lawlor B, Lynch A, Morgan K, Brown KS, Passmore PA, Craig D, McGuinness B, Todd S, Holmes C, Mann D, Smith AD, Love S, Kehoe PG, Hardy J, Mead S, Fox N, Rossor M, Collinge J, Maier W, Jessen $F$, Schürmann B, van den Bussche $H$, Heuser I, Kornhuber J, Wiltfang J, Dichgans M, Frölich L, Hampel H, Hüll M, Rujescu D, Goate AM, Kauwe JS, Cruchaga C, Nowotny P, Morris JC, Mayo K, Sleegers K, Bettens K, Engelborghs S, De Deyn PP, Van Broeckhoven C, Livingston G, Bass NJ, Gurling H, McQuillin A, Gwilliam R, Deloukas P, Al-Chalabi A, Shaw CE, Tsolaki M, Singleton AB, Guerreiro R, Mühleisen TW, Nöthen MM, Moebus S, Jöckel KH, Klopp N, Wichmann HE, Carrasquillo MM, Pankratz VS, Younkin SG, Holmans PA, O'Donovan M, Owen MJ, Williams J: Genomewide association study identifies variants at CLU and PICALM associated with Alzheimer's disease. Nat Genet 2009, 41:1088-93.

10. Lambert JC, Heath S, Even G, Campion D, Sleegers K, Hiltunen M, Combarros O, Zelenika D, Bullido MJ, Tavernier B, Letenneur L, Bettens K, Berr C, Pasquier F, Fiévet N, Barberger-Gateau P, Engelborghs S, De Deyn P, Mateo I, Franck A, Helisalmi S, Porcellini E, Hanon O, European Alzheimer's Disease Initiative Investigators, de Pancorbo MM, Lendon C, Dufouil C, Jaillard C, Leveillard T, Alvarez V, Bosco P, Mancuso M, Panza F, Nacmias B, Bossù P, Piccardi P, Annoni G, Seripa D, Galimberti D, Hannequin D, Licastro F, Soininen H, Ritchie K, Blanché H, Dartigues JF, Tzourio C, Gut I, Van Broeckhoven C, Alpérovitch A, Lathrop M, Amouyel P: Genome-wide association study identifies variants at CLU and CR1 associated with Alzheimer's disease. Nat Genet 2009, 41:1094-9.

11. Blankenberg S, Godefroy T, Poirier O, Rupprecht HJ, Barbaux S, Bickel C, Nicaud V, Schnabel R, Kee F, Morrison C, Evans A, Lackner KJ, Cambien F, Münzel T, Tiret L, AtheroGene Investigators: Haplotypes of the caspase-1 gene, plasma caspase-1 levels, and cardiovascular risk. Circ Res 2006, 99:102-8.

12. McKhaan $G$, Drachman D, Folstein M, Katzman R, Price D, Stadlan EM: Clinical diagnosis of Alzheimer's disease: report of the NINCDA-ADRDA Work Group under the auspices of Department of Health and Human Services Task Force on Alzheimer's Disease. Neurology 1984, 34:934-44.

13. Trompet S, de Craen AJM, Slagboom P, Shepherd J, Blauw GJ, Murphy MB, Bollen ELEM, Buckley BM, Ford I, Gaw A, Macfarlane PW, Packard CJ, Stott DJ, Jukema JW, Westendorp RGJ, PROSPER Group: Genetic variation in the interleukin-1 $\beta$-converting enzyme associates with cognitive function. The PROSPER study. Brain 2008, 131:1069-77.

14. Mondadori CR, de Quervain DJ, Buchmann A, Mustovic H, Wollmer MA, Schmidt CF, Boesiger P, Hock C, Nitsch RM, Papassotiropoulos A, Henke K: Better memory and neural efficiency in young apolipoprotein $E \& 4$ carriers. Cereb Cortex 2007, 17:1934-47.
15. Papassotiropoulos A, Stephan DA, Huentelman MJ, Hoerndli FJ, Craig DW, Pearson JV, Huynh KD, Brunner F, Corneveaux J, Osborne D, Wollmer MA, Aerni A, Colucci D, Hänggi J, Mondadori CRA, Buchmann A, Reiman EM, Caselli RJ, Henke K, de Quervain DJF: Common KIBRA alleles are associated with human memory performance. Science 2006, 314:475-8

16. Schaper K, Holsch H, Popp J, Wagner M, Jessen F: KIBRA gene variants are associated with episodic memory in healthy elderly. Neurobiol Aging 2008, 29:1123-5.

17. Rodríguez-Rodríguez E, Infante J, Llorca J, Mateo I, Sánchez-Quintana C, García-Gorostiaga I, Sánchez-Juan P, Berciano J, Combarros O: Agedependent association of KIBRA genetic variation and Alzheimer's disease risk. Neurobiol Aging 2009, 30:322-4.

\section{Pre-publication history}

The pre-publication history for this paper can be accessed here:http://www biomedcentral.com/1471-2350/11/32/prepub

doi:10.1186/1471-2350-11-32

Cite this article as: Vázquez-Higuera et al:: Caspase-1 genetic variation is not associated with Alzheimer's disease risk. BMC Medical Genetics 2010 11:32.

\section{Submit your next manuscript to BioMed Central and take full advantage of:}

- Convenient online submission

- Thorough peer review

- No space constraints or color figure charges

- Immediate publication on acceptance

- Inclusion in PubMed, CAS, Scopus and Google Scholar

- Research which is freely available for redistribution 